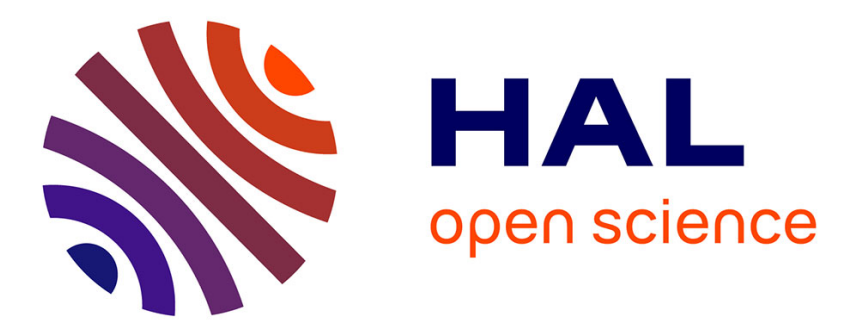

\title{
One-dimensional Analysis Method for Cavitation Instabilities of a Rotating Machinery
}

Satoshi Kawasaki, Masaharu Uchiumi, Takashi Shimura, Yuka Iga

\section{To cite this version:}

Satoshi Kawasaki, Masaharu Uchiumi, Takashi Shimura, Yuka Iga. One-dimensional Analysis Method for Cavitation Instabilities of a Rotating Machinery. 16th International Symposium on Transport Phenomena and Dynamics of Rotating Machinery, Apr 2016, Honolulu, United States. hal-01890078

\section{HAL Id: hal-01890078 https://hal.science/hal-01890078}

Submitted on 8 Oct 2018

HAL is a multi-disciplinary open access archive for the deposit and dissemination of scientific research documents, whether they are published or not. The documents may come from teaching and research institutions in France or abroad, or from public or private research centers.
L'archive ouverte pluridisciplinaire HAL, est destinée au dépôt et à la diffusion de documents scientifiques de niveau recherche, publiés ou non, émanant des établissements d'enseignement et de recherche français ou étrangers, des laboratoires publics ou privés. 


\title{
One-dimensional Analysis Method for Cavitation Instabilities of a Rotating Machinery
}

\author{
Satoshi Kawasaki ${ }^{1 *}$, Masaharu Uchiumi ${ }^{1}$, Takashi Shimura ${ }^{1}$ and Yuka Iga ${ }^{2}$
}

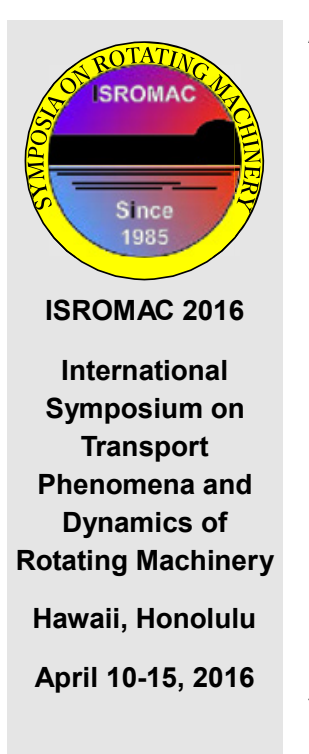

\begin{abstract}
Rotating cavitation is an important problem, which makes it difficult to design reliable rotating machines. In the present study, a simple analysis method that tried to evaluate the cavitation instabilities of a rotating machinery by using one-dimensional system analysis software was attempted. In this method, cavitation compliance and mass flow gain factor are distributed in each flow path of the inducer.

Analysis results show that cavitation instabilities, including rotating phenomena, exist. With the evolved analysis model, effects of various parameters on the eigenvalues of the system were investigated. Analysis results agreed with inducer test results qualitatively. Furthermore, by the analysis considered whirl motion of the rotor, effects of it on cavitation instabilities were investigated.

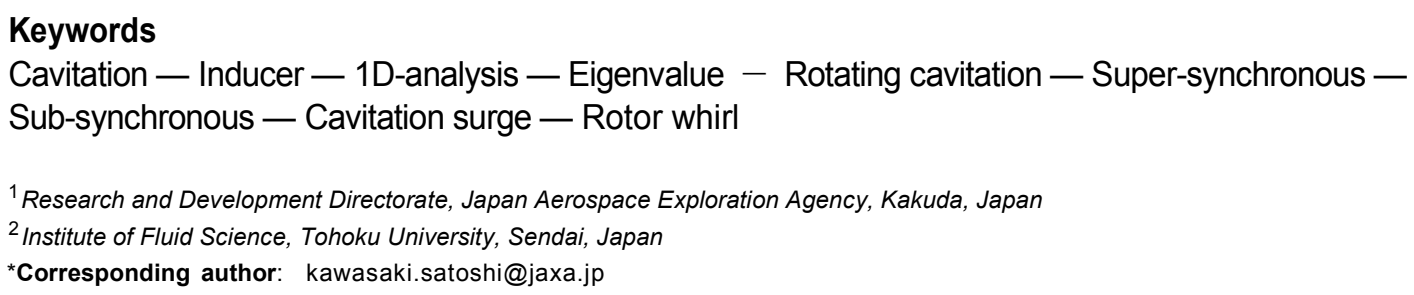

\section{Keywords} Cavitation - Inducer - 1D-analysis - Eigenvalue - Rotating cavitation - Super-synchronous -

${ }^{1}$ Research and Development Directorate, Japan Aerospace Exploration Agency, Kakuda, Japan

${ }^{2}$ Institute of Fluid Science, Tohoku University, Sendai, Japan

\section{INTRODUCTION}

Rotating cavitation was identified about 40 years ago [1]. It is one of the most important problems in high-speed rocket turbopumps. Theoretical and numerical analyses (two- and three-dimensional) of rotating cavitation have been performed to elucidate the instability mechanism [2][3]. Computational fluid dynamics (CFD) is very useful, but too many resources are needed to analyze whole systems including suction lines, discharge lines and inducers parametrically. Therefore, establishment of a one-dimensional analysis method to analyze fluid systems, including dynamic characteristics of cavitating inducer, was attempted.

A method to analyze pump dynamic characteristics by cavitation compliance, mass-flow gain factor and dynamic gain has been reported [4][5]. This analysis method has been used to analyze one-dimensional phenomena such as surge phenomenon in the past. For example, POGO, which is an auto-oscillation where the thrust oscillation of rocket propulsion system including turbopumps is coupled with the natural frequency of the rocket structure, has been analyzed using this method [6][7]. In the present study, this one-dimensional analysis method was further developed in order to analyze rotating cavitation too, using one-dimensional multi-domain system analysis software AMESim [8]. This software has been used to analyze system stability of a self-balancing type axial-thrust balancing-system in the past [9]. In this software, physical systems are described by connecting sub-models which transfer energy to each other. Cavitation compliance and mass-flow gain factor were distributed to each flow path of an inducer, and evaluation of the possibility of analyzing rotating phenomena such as rotating cavitation by this one-dimensional analysis method was attempted. Rotating cavitation is closely related to whirling motion of the rotor assembly and a study of non-linear modeling of excitation force and rotor whirling has been reported [10]. Whirling motion was also accounted for by variable flow area orifices which connect with the next flow path in the present analysis. The variation of leakage flow rate through the tip clearance of each blade is simulated by the motion of the variable flow area orifices. With the improved analysis model, effects of various parameters on the eigenvalues of the system were investigated. Analysis results showed that rotating phenomena existed and agreed with inducer test results qualitatively. This analysis method is considered to be able to contribute to the development of a dynamic design method for turbopumps [11] and to be applicable to the analysis of other rotating machineries.

\section{METHODS}

\subsection{Modeling of a three-bladed inducer}

Figure 1 shows a modeling image of a three-bladed inducer. It is assumed that rotating cavitation is caused by the characteristics of fluid motion in the flow paths divided by inducer blades. Hence, the three-bladed inducer is represented by three simplified pipes and cavity oscillation is considered to occur inside the each pipe. Leakage flows from tip clearances are described by variable flow area orifices connecting the middle of the path and the inlet of the next path. The areas of the orifices are changed harmonically and the oscillation phase of each orifice is given according to the number of blades. The steady flow rate of the leakage flow is given by the mean flow area of the variable orifice and dynamic flow rate caused by rotor whirl is given by the amplitude and phase of flow area variation. The flow rate of the next 


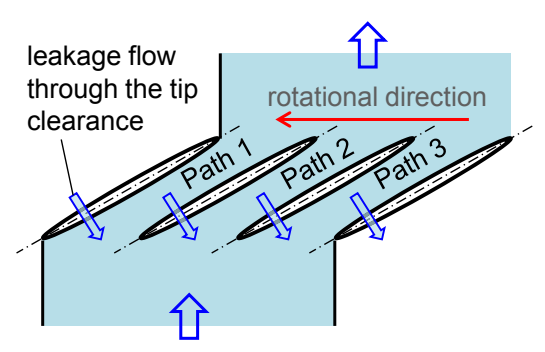

three-bladed inducer

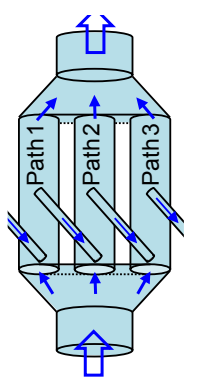

three pipes model

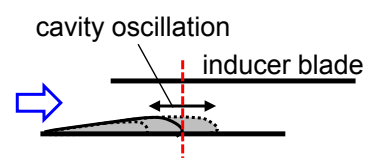

path between the blades location of cavity oscillation

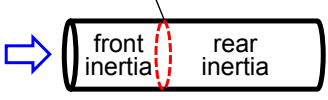

pipe model

Figure 1 Modeling image of three-bladed inducer

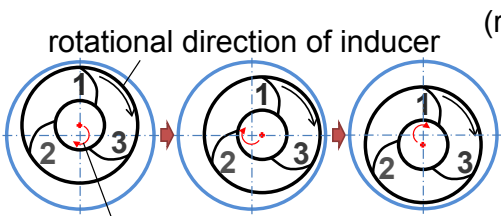

moving coordinate system (rotating with inducer)

whirling direction of rotor

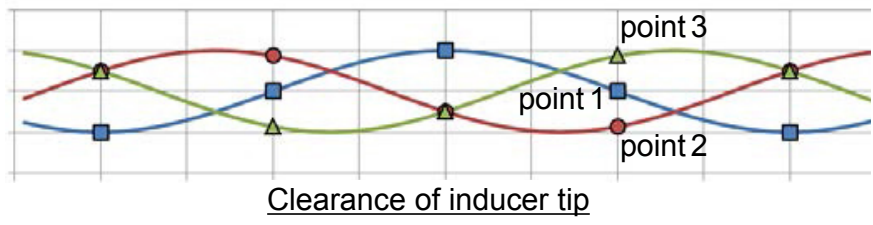

Figure 2 Simulation of inducer tip clearance with rotor whirling

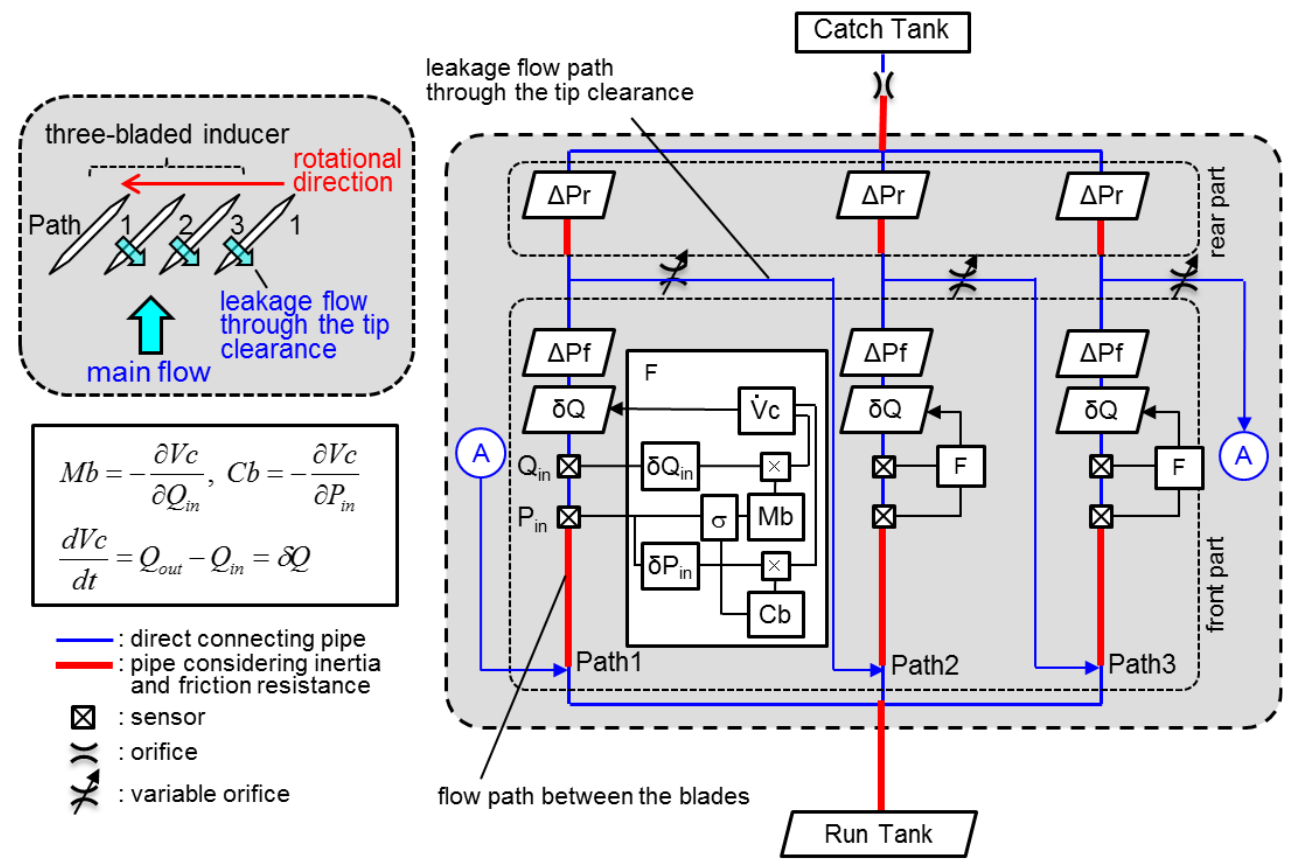

Figure 3 Schematic diagram of the analysis model for inducer test loop

path is changed by the leakage flow rate. Figure 2 shows inducer tip clearance variation caused by whirling motion of a three-bladed inducer. In the present model, moving coordinate rotating with the inducer is applied. The number of each blade is assigned in series in the direction of counter rotation, as shown in Fig. 2. The inducer tip clearance varies in the sequence of path $1 \mathrm{first}$, path 3 second and path 2 third in the case of super-synchronous whirling motion.

Figure 3 shows a schematic diagram of the whole analysis model used in the present study. The model represents the blowdown type test loop. The test inducer and the run tank are connected by the inlet pipe model considering the inertia. The inducer and the catch tank are connectted by the discharge pipe model considering the inertia and the orifice for flow rate control is located between the discharge pipe and the catch tank. In the inducer model, each flow path is divided into a front part and a rear part. The inducer delivery head is divided into two and distributed to the front part and the rear part, respectively. In this study, the head was equally divided in half tentatively. Furthermore, the inertia of each flow path was divided at the location that occurs cavity oscillation and distributed.

In this model, the cavitation compliance and mass flow gain factor are distributed to the three paths and calculated by the inlet pressure of the each path. The definition of cavitation compliance and that of mass flow gain factor are shown in Fig. 3. Cavitation compliance is defined as the cavity volume change rate to the inlet pressure change. Mass flow gain is determined as the cavity volume change rate to the inlet flow change. The flow difference between upstream and downstream of the cavity is obtained by time derivation of cavity volume. In this model, inducer is represented by the parallel paths so that the cavitation compliance of whole inducer is represented by summation of those three paths and the mass flow gain factor is equal to each three paths in 
steady condition.

In the analysis model using the one-dimensional multi-domain system analysis software, the fluid system is described by connecting fluid sub-models such as tanks, variable orifices, pipes, etc. Values of cavitation number, head coefficient, etc. are calculated by function sub-models and transmitted to each other through signal lines.

\subsection{Analysis inducer and conditions}

The model analyzed was a three-bladed inducer for a 100 -ton class rocket engine hydrogen turbopump. The rotational speed is $42500 / 60=708 \mathrm{~Hz}$ and the mass flow rate is $37.3 \mathrm{~kg} / \mathrm{s}$ at nominal operating point. Nominal tip clearance is about $0.5 \%$ of the inducer tip radius. Unless otherwise mentioned, tip clearance at each blade was constant at a nominal value.

The cavitation compliance and mass flow gain factor were calculated by the approximate expressions, which were obtained by nondimensionalized test results in the past [12]. This test had been carried out by generating sinusoidal perturbation in the pump flow. Figure 4 shows the test results and the approximate expressions on the CASE 1 inducer. In the CASE 1 inducer, super-synchronous rotating cavitation was clearly observed. Dimensionalized values were given by substituting operating rotational speed, cavitation number, etc., in the process of calculation. Pump dynamic gain

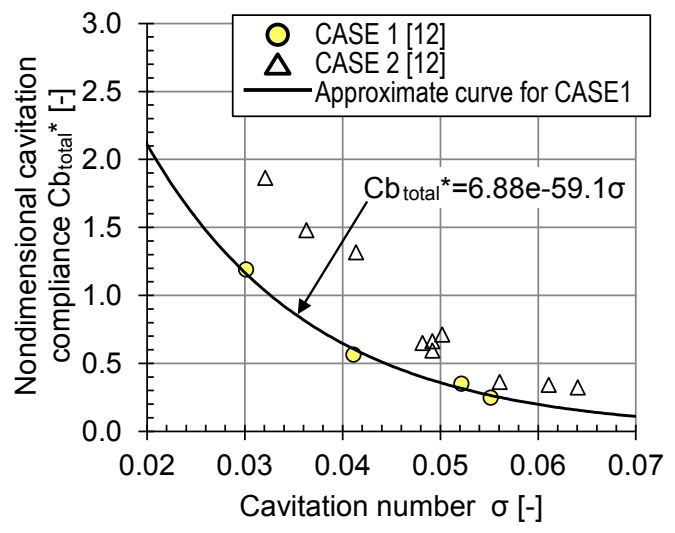

(a) Cavitation compliance

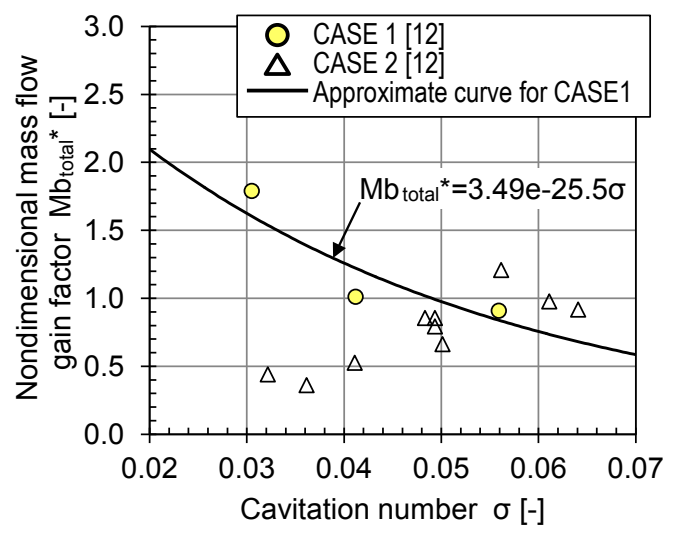

(b) Mass flow gain factor

Figure 4 Approximate formulas of cavitation compliance and mass flow gain factor used by the present analysis was assumed to be zero in the present analysis because rotating cavitation occurs in the region of relatively large cavitation number. The fluid system analysis was conducted with single-phase flow. The working fluid was liquid hydrogen and the fluid properties (density, viscosity, compressibility, etc.) are given by polynomial approximation.

\section{RESULTS AND DISCUSSION}

\subsection{Modal analyses of cavitation instabilities}

In order to confirm the existence of oscillation modes caused by cavitation, frequency domain analysis of the system was carried out. Figure 5 shows the eigenvalues of the system for various cavitation numbers $\sigma$ on the complex plane. When the eigenvalue of the oscillation mode has a positive real part, this mode is unstable. The ellipse line represents the iso-frequency line and the radial line represents the iso-damping ratio line. In some oscillation modes (MODE-A, MODE-B and MODE-C), the natural frequencies and the damping ratios changed with the cavitation number. If the eigenvalue of oscillation mode is not influenced by cavitation, the natural frequency and the damping ratio are constant with change of cavitation number. Therefore, it is considered that these modes are related to cavitation phenomena.

Figure 6 shows comparison with the natural frequency and damping ratio of MODE-A, MODE-B and MODE-C. In the case of MODE-A and MODE-B, the natural frequencies and the damping ratios decreased with decreasing cavitation number. Meanwhile, in the case of MODE-C, natural frequency also decreased with decreasing cavitation number. However, the damping ratio was not much changed with decreasing cavitation number.

To investigate these oscillation modes caused by cavitation, modal analysis was carried out. The results of modal analysis for MODE-A, MODE-B and MODE-C are shown in Fig. 7(a), (b) and (c), respectively. The cavitation number for this analysis is $\sigma=0.04$. The lower graph shows the amplitude change of the mass flow rate at the inlet of path 1, path 2 and path 3 (see Fig. 1) for 5 cycles. The upper graph shows the comparison with the amplitudes of mass flow rate of these paths at the time of the bold line in the lower graph.

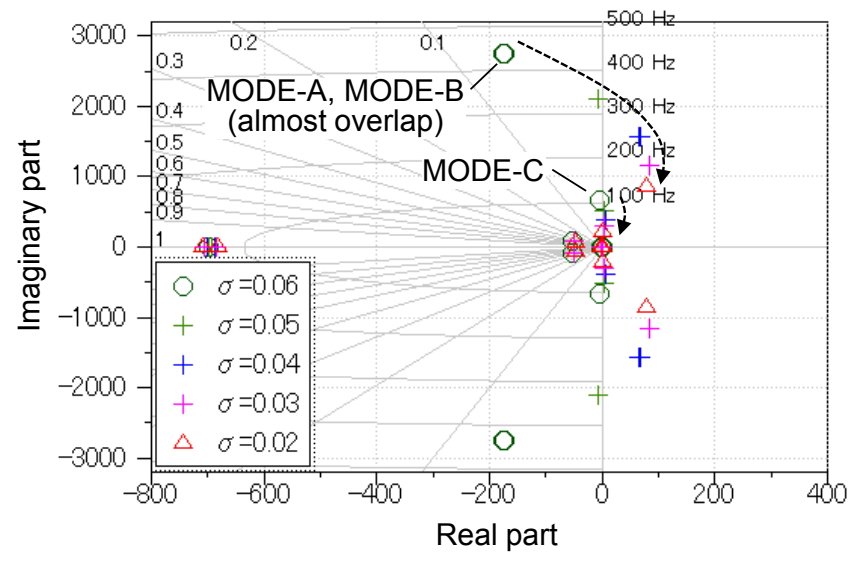

Figure 5 Root-locus plot of the system 


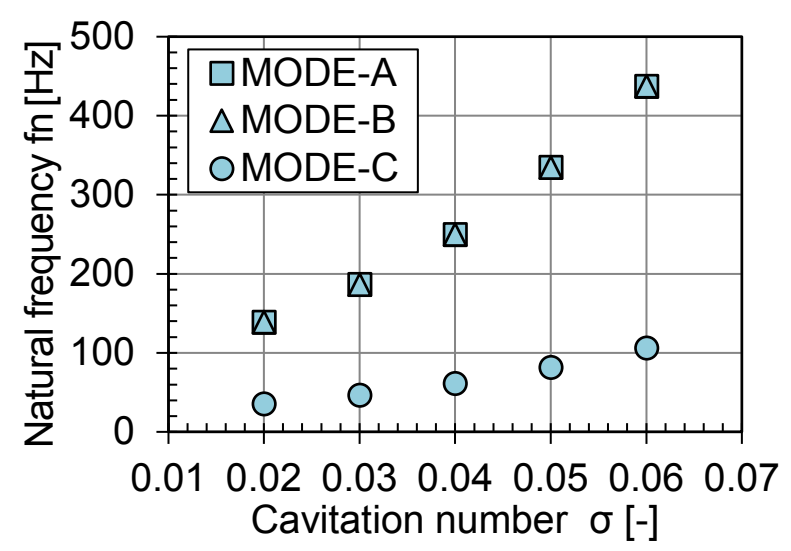

(a) Natural frequency

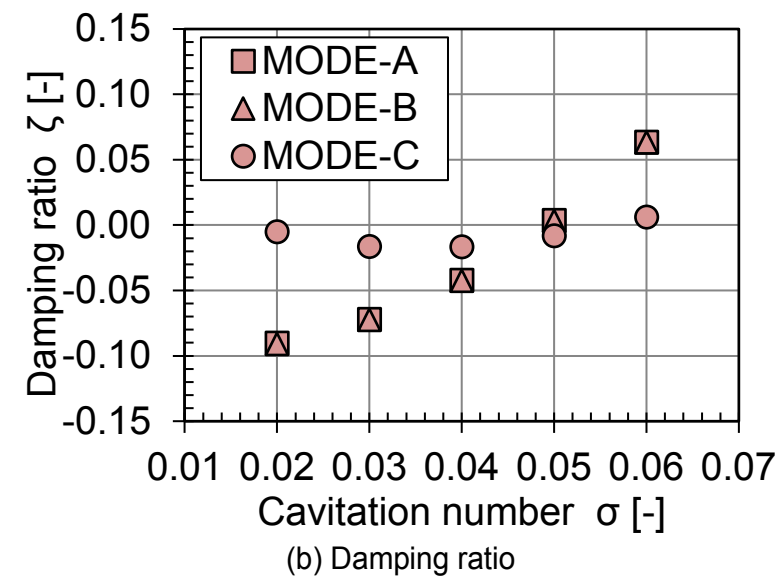

Figure 6 Eigenvalues of MODE-A, B and C

\subsubsection{MODE-A}

The flow rate fluctuation of MODE-A propagated in the order of path 1, path 3 and path 2 as shown in Fig. 7(a). In the present analysis model, moving coordinate system rotating with the inducer was applied, and the inducer rotated in the order of path 1 , path 3 and path 2 as shown in Fig. 1. Since the fluctuation of the flow rate propagated in the same direction as that of inducer rotation, it seems to propagate at higher speed than inducer rotation speed in the fixed coordinate system. In this case, the propagating frequency in the fixed coordinate system changed from 1.62 to 1.20 times the rotation frequency with decreasing cavitation number $\sigma$ from 0.06 to 0.02 . In the reference paper [13], the propagating frequency had changed from 1.25 to 1.10 times the rotation frequency with decreasing cavitation number $\sigma$ from 0.06 to 0.045 . Although there is quantitative difference of the propagation frequency, the tendency of the frequency change to the variation of cavitation number qualitatively agrees with the phenomenon of super-synchronous rotating cavitation which had been observed in the inducer test [13][14]. The damping ratio of MODE-A became negative with lower cavitation number as seen in Fig. 6(b). Hence, the unstable fluctuation is possibly caused when the inlet pressure of the inducer decreases. The results suggest that MODE-A represents the mode of super-synchronous rotating cavitation (SP-RC).

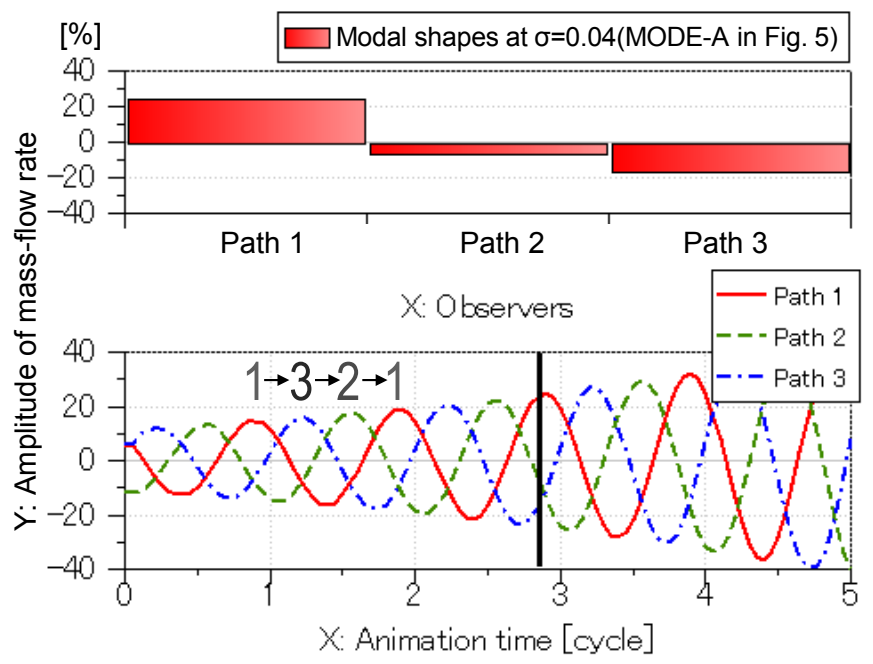

(a) MODE-A (Super-synchronous rotating cavitation mode)

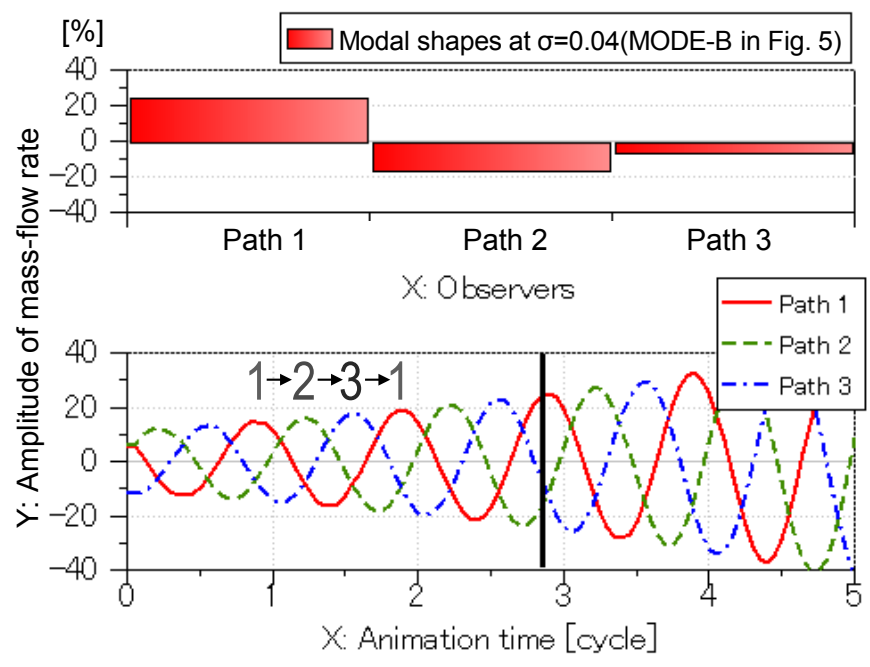

(b) MODE-B (Sub-synchronous rotating cavitation mode)

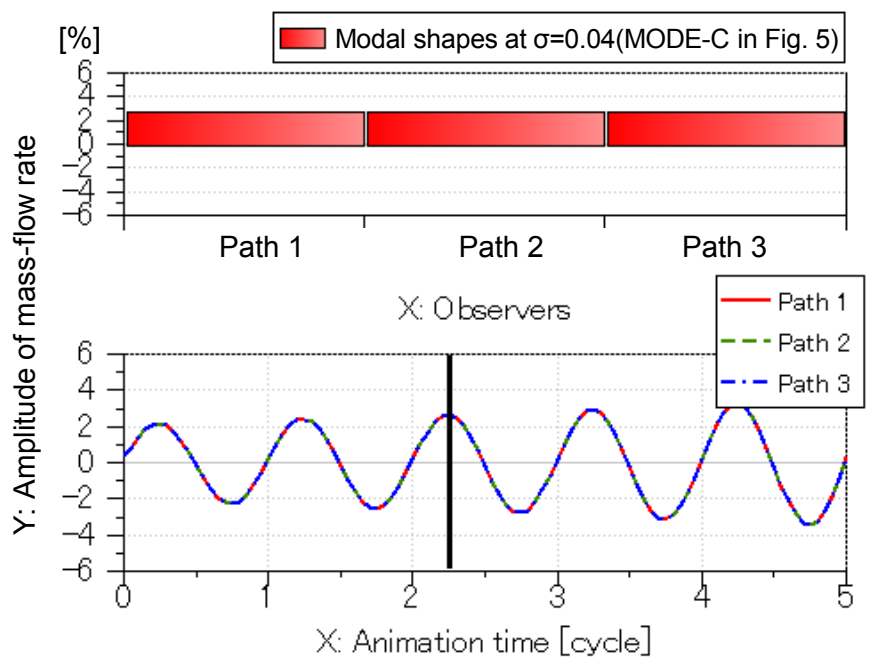

(c) MODE-C (Cavitation surge mode)

Figure 7 Flow rate fluctuations of three-bladed inducer 
Table 1 Comparison of damping ratio for modes at $\sigma=0.04$

\begin{tabular}{|c|c|c|}
\hline Mode & $\begin{array}{c}\text { Natural freaquency } \\
\mathrm{fn}[\mathrm{Hz}]\end{array}$ & $\begin{array}{c}\text { Damping ratio } \\
\zeta[-]\end{array}$ \\
\hline SP-RC (MODE-A) & 145 & -0.0104 \\
\hline SB-RC (MODE-B) & 145 & -0.0111 \\
\hline CS (MODE-C) & 37 & 0.0112 \\
\hline
\end{tabular}

\subsubsection{MODE-B}

Figure $7(\mathrm{~b})$ shows the flow rate fluctuation of MODE-B. Propagation of the flow rate fluctuation was similar to that of MODE-A. However, the direction of propagation was opposite to that of MODE-A. Therefore, the flow rate fluctuation seems to propagate at lower speed than the inducer rotation speed in the fixed coordinate system. In this case, the frequency of the flow rate fluctuation in the fixed coordinate system changed from 0.38 to 0.80 times the rotating frequency with decreasing cavitation number $\sigma$ from 0.06 to 0.02 . These results suggest that MODE-B represented the mode of sub-synchronous rotating cavitation (SB-RC), which had also been observed in the inducer test [13][14]. Furthermore, the result of theoretical analysis [2] indicated that both SP-RC and SB-RC modes exist, in agreement with the present result.

Table 1 shows the damping ratios of MODE-A and MODE-B in cases with or without tip clearance. The damping ratio of MODE-B was slightly smaller than that of MODE-A in the case with tip clearance. In the case without tip clearance, which means no leakage flow in inducer, the damping ratios of both modes were the same and larger negative than those in the case with tip clearances. This result suggests that leakage flow through the tip clearance affects the difference of damping ratio between the SP-RC mode and the SB-RC mode and that the leakage flow enables both modes to improve the stability.

\subsubsection{MODE-C}

Figure 7(c) shows the flow rate fluctuation of MODE-C. In the lower graph, all lines of amplitude overlap. The flow rate fluctuation in each path occurs in the same phase with the same amplitude. The result suggests that MODE-C represents the mode of cavitation surge (CS).

\subsection{Effects of cavitation compliance and mass flow gain factor on eigenvalues}

\subsubsection{Effect of cavitation compliance}

Figure 8 shows the variations of eigenvalues due to the cavitation compliance at cavitation number $\sigma=0.04$. Cavitation compliance changed from $1 / 4$ to 4 times the value obtained by approximate expression. Natural frequencies of the SP-RC mode, the SB-RC mode and the CS mode decreased with increasing cavitation compliance. By contrast, damping ratios increased with increasing cavitation compliance.

It has been indicated that the increase of cavitation compliance has a stabilizing effect on low frequency oscillation in the system as shown by another stability analysis for the pump loop system [5]. This result agrees

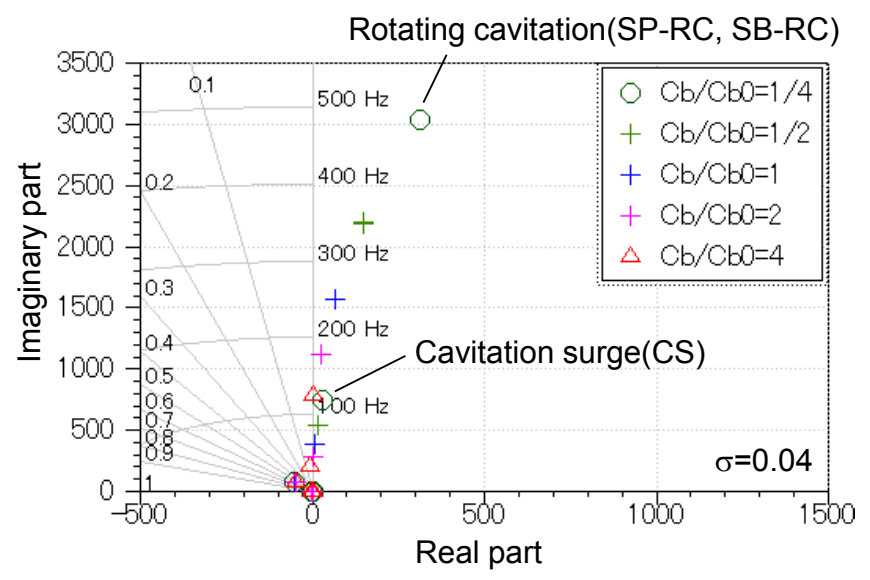

(a) Root-locus plot

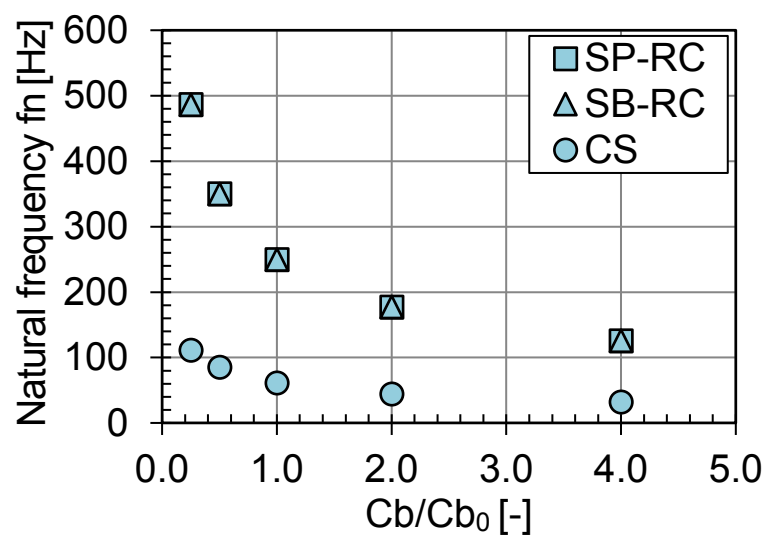

(b) Natural frequency

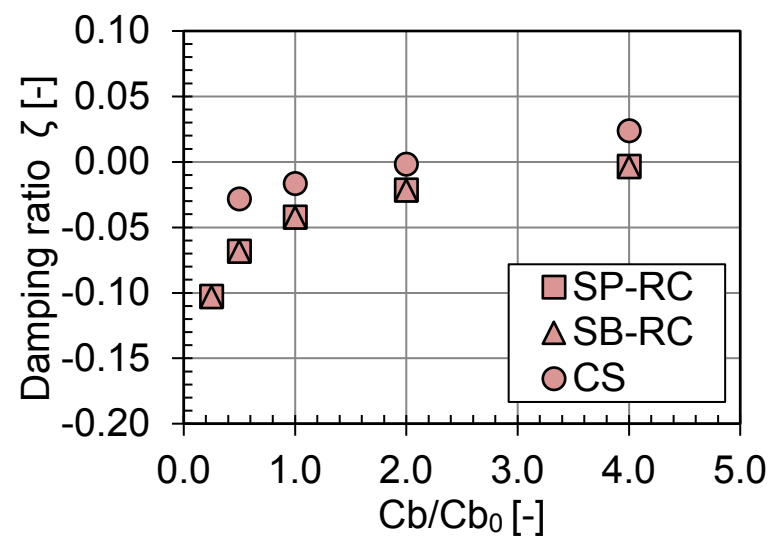

(c) Damping ratio

Figure 8 Effects of cavitation compliance on eigenvalues $(\sigma=0.04)$

with the effect of cavitation compliance for the CS mode by the present analysis.

\subsubsection{Effect of mass flow gain factor}

Figure 9 shows the variations of eigenvalues due to the mass flow gain factor at cavitation number $\sigma=0.04$. The mass flow gain factor changed from $1 / 4$ to 4 times the value obtained by approximate expression. Unlike the effect on cavitation compliance, natural frequencies of the SP-RC mode, the SB-RC mode and the CS mode were almost constant with increasing mass flow gain factor and damping ratios decreased with increasing mass flow gain 
factor.

Enlargement of the housing diameter at the inducer inlet has been known to be one way to suppress rotating cavitation. It has been reported test results showed that the mass flow gain factor decreased due to this treatment [12]. This result is agreement with the effect of mass flow gain factor for rotating cavitation mode by the present analysis.

\subsection{Step response by time domain analysis}

In order to simulate the instability phenomenon caused by the oscillation modes of the inducer, especially rotating

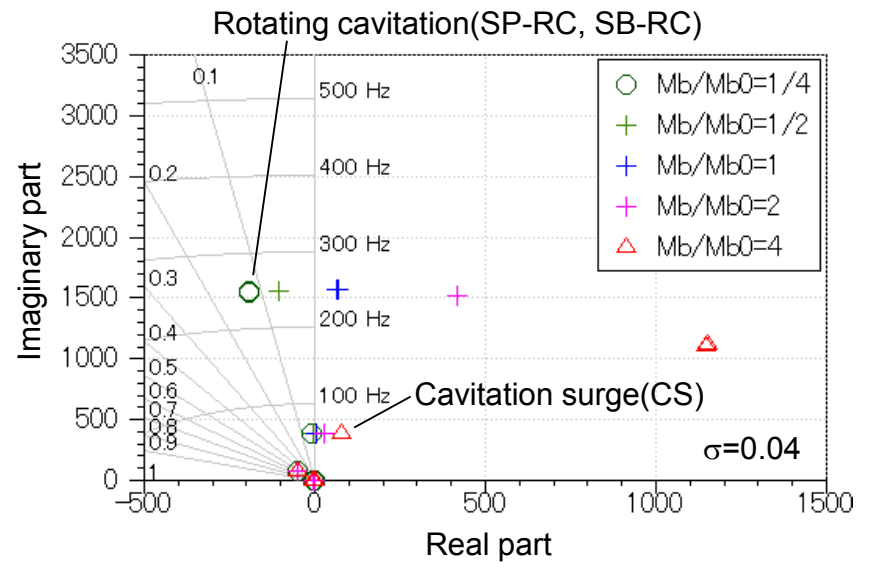

(a) Root-locus plot

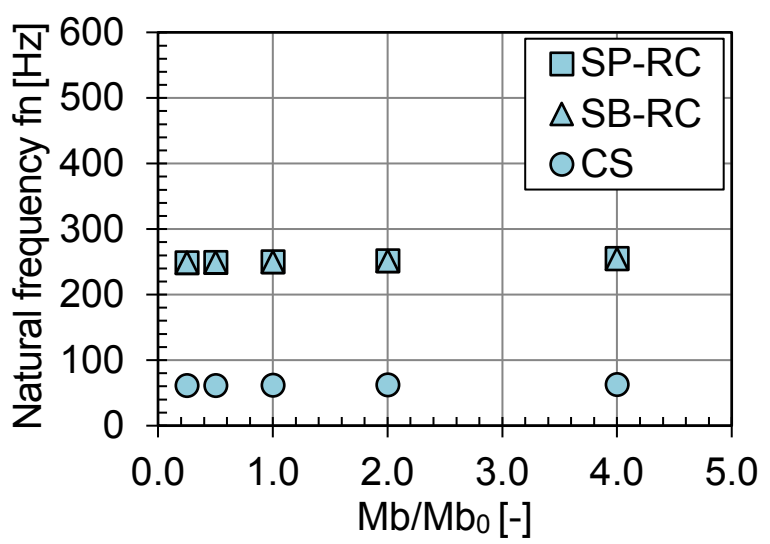

(b) Natural frequency

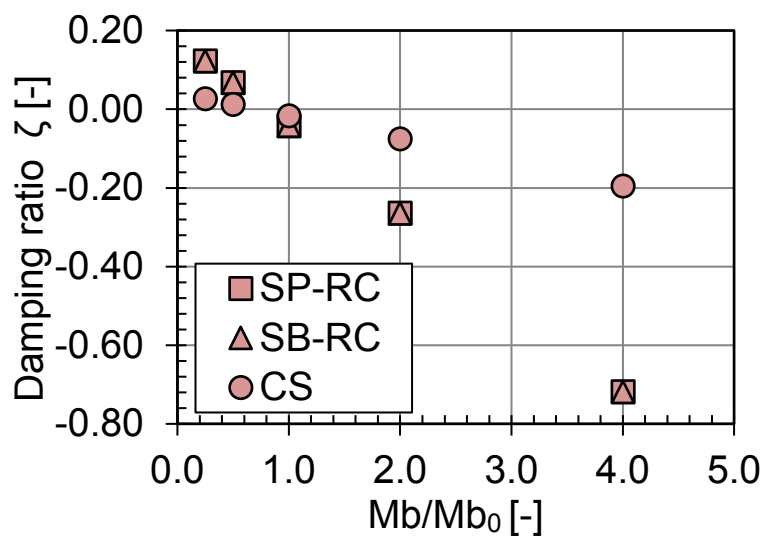

(c) Damping ratio

Figure 9 Effects of mass flow gain factor on eigenvalues $(\sigma=0.04)$ cavitation, time domain analysis was carried out in the present model. Table 2 shows eigenvalues of the oscillation modes under the analysis conditions $(\sigma=0.03$, $\left.C b / C b_{0}=3, M b / M b_{0}=1\right)$, where the damping ratio of $C S$ mode is positive but these of SP-RC mode and SB-RC mode are both negative. Consequently, it is considered that instability phenomenon caused by the rotating cavitation modes appears more strongly than that by cavitation surge mode. The step change of pressure in the run tank was given and then the response of the system was observed. The upper graph in Fig. 10(a) shows the time histories of the tank pressure, the inlet pressure of inducer and the pressures of three paths. The lower graph in Fig. 10(a) shows the frequency analysis results of the fluctuations of these pressures by FFT.

After the step change of pressure in run tank, low frequency fluctuations of the inlet pressure of the inducer and the pressures of the three paths occurred with the same phase. The frequencies of the pressure fluctuations were slightly less than $30 \mathrm{~Hz}$, which approximately corresponded to the natural frequency of the CS mode. Hence, the oscillation phenomenon of these low frequency fluctuations is assumed to be the CS mode. According to the positive damping ratio of the CS mode (see Table 2), the amplitude of the fluctuation gradually decreased with time. After the fluctuation of the CS mode

Table 2 Eigenvalues of oscillation modes $\left(\sigma=0.03, C b / C b_{0}=3, M b / M b_{0}=1\right)$

\begin{tabular}{|c|c|c|}
\hline Mode & $\begin{array}{c}\text { Natural freaquency } \\
\mathrm{fn}[\mathrm{Hz}]\end{array}$ & $\begin{array}{c}\text { Damping ratio } \\
\zeta[-]\end{array}$ \\
\hline SP-RC (MODE-A) & 108 & -0.0234 \\
\hline SB-RC (MODE-B) & 108 & -0.0242 \\
\hline CS (MODE-C) & 29 & 0.0365 \\
\hline
\end{tabular}

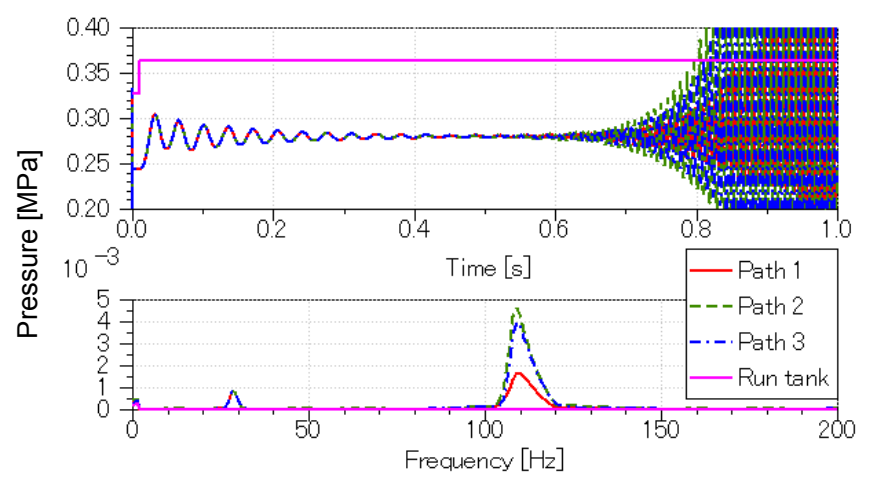

(a) Mode change from cavitation surge to rotating cavitation

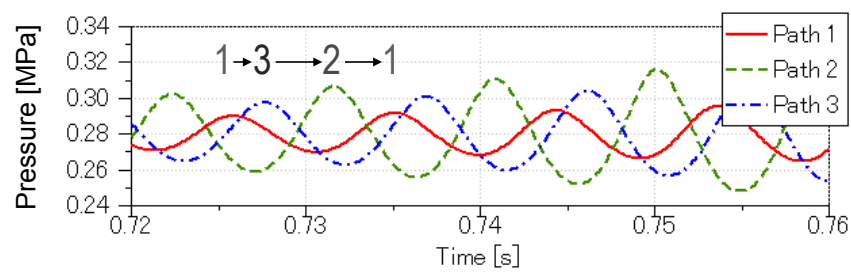

(b) Pressure fluctuation caused by rotating cavitation

Figure 10 Step response of the system $\left(\sigma=0.03, C b / C b_{0}=3, M b / M b_{0}=1\right)$ 
disappeared, high frequency fluctuations occurred and exponentially increased. Figure 10(b) shows the high frequency fluctuations in detail. The pressure of each of the three paths fluctuated with the different phases. The frequencies of the pressure fluctuations were about 110 $\mathrm{Hz}$, which approximately corresponded with the natural frequency of rotating cavitation modes (SP-RC or SB-RC). Since these fluctuations propagated in the order of path 1 , path 3 and path 2, the oscillation phenomenon of these high frequency fluctuations is assumed to be the SP-RC mode. According to the negative damping ratio of the SB-RC mode (see Table 2), amplitude of the fluctuation was exponentially increased with time, and then the fluctuations diverged.

SB-RC mode was not observed in this simulation. However, if the step size or the step direction of pressure given in run tank was changed, SP-RC mode appeared in some cases. As seen in Table 2, the difference of the damping ratio between the SP-RC mode and the SB-RC mode is not so large, so that it is considered that the determination of the fluctuation mode of rotation cavitation was not affected by this difference of the damping ratio.

\subsection{Response to the whirling motion of the rotor}

In actual rotating machinery, whirling motion of the rotor often occurs. In order to investigate the effect of such whirling motion of the rotor on cavitation instabilities, the

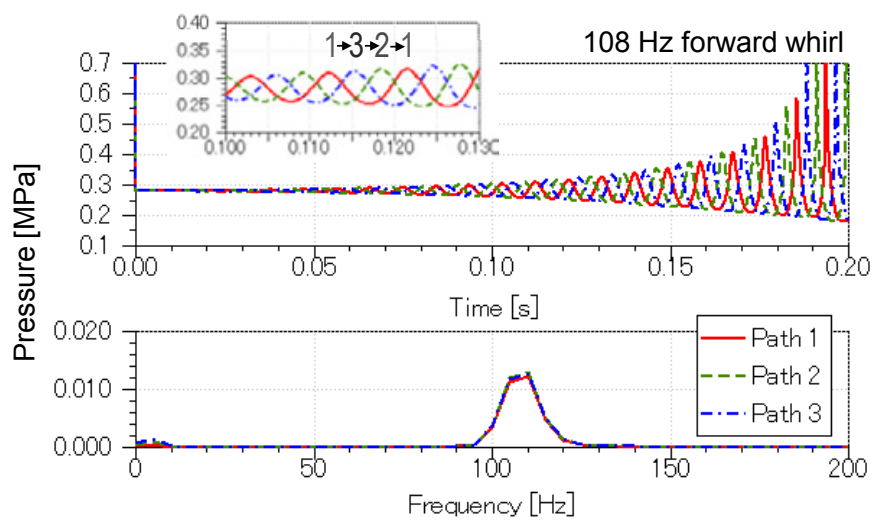

(a) $108 \mathrm{~Hz}$ forward whirl

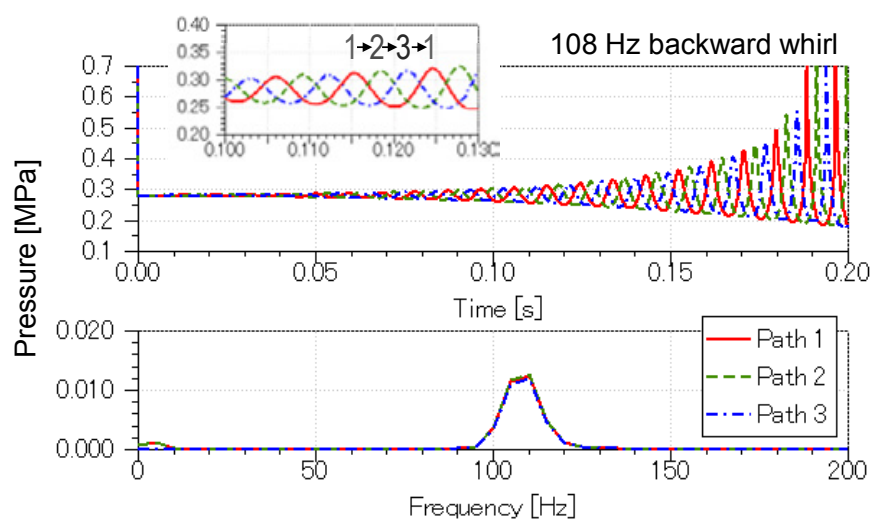

(b) $108 \mathrm{~Hz}$ backward whirl

Figure 11 Response to the $108 \mathrm{~Hz}$ whirling motion of rotor: $105 \mathrm{~Hz}$ is same as the eigenvalue of rotating cavitation mode $\left(\sigma=0.03, C b / C b_{0}=3, M b / M b_{0}=1\right)$ simulation accounted for the whirling motion of rotor was carried out by time domain analysis. The method used to simulate the whirling motion of the rotor was presented in section 1.1. Figure 11(a) and (b) show the time histories of the pressure of each of the three paths and FFT results with forward whirl and backward whirl, respectively. The whirl amplitude was $2 \%$ of the nominal tip clearance and the cavitation number, the cavitation compliance and the mass-flow gain factor were same as these of step response analysis in section 2.3. The whirl frequency was $108 \mathrm{~Hz}$, as the same as the natural frequency of the SP-RC mode and the SB-RC mode. When the forward whirling motion was inputted, pressure fluctuation occurred and grew. The frequency of the fluctuation was a little over $100 \mathrm{~Hz}$ and the fluctuation propagated in the order of path 1 , path 3 and path 2 . Therefore, the fluctuation phenomena with forward whirl is assumed to be the SP-RC mode. On the other hand, when the backward whirling motion was inputted, pressure fluctuation with frequency of $108 \mathrm{~Hz}$ also occurred and grew. However, the fluctuation propagated in the order of path 1 , path 2 and path 3 . Therefore, the fluctuation phenomenon with backward whirl is assumed to be the SB-RC mode.

Furthermore, in order to investigate the effect of whirl frequency and duration time of whirling motion, time domain analysis was carried out, whirling motion with a frequency of $50 \mathrm{~Hz}$ from 0 to $0.01 \mathrm{sec}$ being inputted.

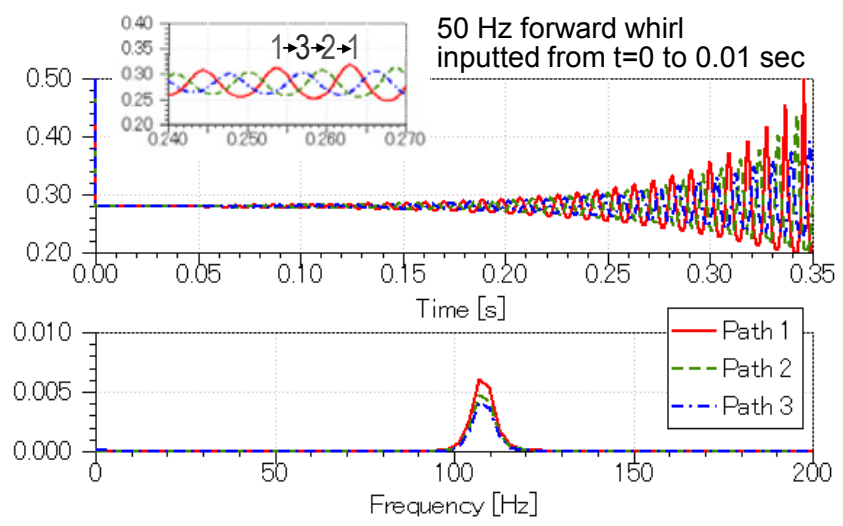

(a) $50 \mathrm{~Hz}$ forward whirl inputted from $t=0$ to $0.01 \mathrm{sec}$
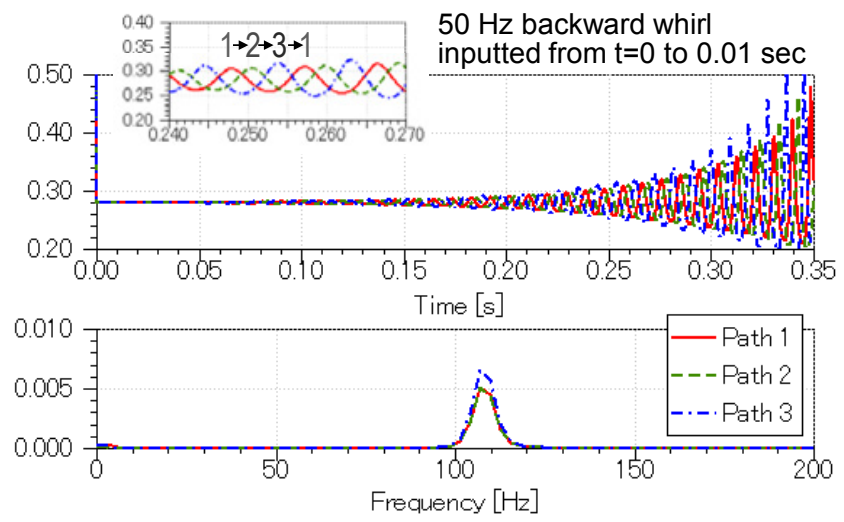

(b) $50 \mathrm{~Hz}$ backward whirl inputted from $t=0$ to $0.01 \mathrm{sec}$

Figure 12 Response to the $50 \mathrm{~Hz}$ whirling motion of rotor $\left(\sigma=0.03, C b / C b_{0}=3, M b / M b_{0}=1\right)$ 
After $0.01 \mathrm{sec}$, whirling motion was stopped and tip clearance at each blade was kept constant at the nominal value. Figure 12 (a) and (b) show the time histories of pressure of each of the three paths and FFT results with forward whirl and backward whirl, respectively. With both forward and backward whirl, pressure fluctuations with a frequency of $105 \mathrm{~Hz}$ occurred and the propagating direction of the pressure fluctuation was the same as that of the whirl direction. Therefore, the fluctuation phenomena caused by forward whirl and backward whirl are assumed to be the SP-RC mode and the SB-RC mode, respectively. In both cases, after the whirling motion was stopped, pressure fluctuations grew and finally diverged. Although the damping ratio of the SP-RC mode was less negative than that of the SB-RC mode, fluctuation of SP-RC mode was not replaced by that of the SB-RC mode.

The results indicate the whirling motion of rotor affects the determination of the propagating direction of the rotating cavitation mode.

\section{CONCLUSIONS}

A simple one-dimensional analysis method to investigate the dynamics of the fluid system of the rotating machinery was established. Applying this method to a rocket turbopump inducer, the existence of cavitation instabilities such as rotating cavitation and cavitation surge were confirmed and the following conclusions were obtained.

(1) The method to distribute cavitation compliance and mass flow gain factor to the paths between the blades enables the simulation of the cavitation instability of rotating phenomena, such as rotating cavitation, even by using the one-dimensional analysis method.

(2) The effects of whirling motion of the rotor on cavitation instabilities were investigated. The results suggested that whirling motion of the rotor affects the propagating direction of fluctuations caused by rotating cavitation mode.

(3) The effects of cavitation compliance and mass flow gain factor on the eigenvalues of the system were investigated. The results, such as the stabilizing effect on cavitation surge by increase of cavitation compliance and suppressing effect on rotating cavitation by decrease of mass flow gain factor, agree with the results obtained by past experimental and analytical studies qualitatively.

(4) It is considered that rotor vibration related to the cavitation instability of rotating phenomena can be analyzed by coupling with rotor motion analysis and the present analysis.

(5) The present calculation is completed within 1 minute per case by a typical personal computer. This method of analysis is quite useful for carrying out many parametric studies.

As the analysis results, it is confirmed that the cavitation compliance and mass flow gain factor are affect to the cavitation instabilities. However, it is not possible to calculate the cavitation compliance and mass flow gain factor by using the present analysis. Therefore, it is very important to investigate and model the characteristics of these factors such as the effect of flow rate and the frequency characteristics. By using these characteristics models, it will be possible to simulate the cavitation instabilities accurately and helpful to understand the mechanism of the cavitation instabilities.

\section{NOMENCLATURE}

$A_{i}$ : inducer inlet area $\left(\mathrm{m}^{2}\right)$

$\mathrm{Cb}$ : cavitation compliance in each path $\left(\mathrm{m}^{4} \mathrm{~s}^{2} / \mathrm{kg}\right)$

$C b^{*}$ : Nondimensional cavitation compliance in each path, $C b^{*}=C b /\left(2 \pi D_{t} A_{i} / n_{b} \rho U_{t}^{2}\right)$

$D_{t}$ : inducer tip diameter $(\mathrm{m})$

$\mathrm{fn}$ : natural frequency $(\mathrm{Hz})$

$M b$ : mass flow gain factor in each path (s)

$M b^{*}$ : Nondimensional mass flow gain factor in each path, $M b^{*}=M b /\left(\pi D_{t} / n_{b} U_{t}\right)$

$n_{b}$ : number of inducer blades (number of inducer paths)

$P_{\text {in }}:$ pressure at inducer path inlet $(\mathrm{Pa})$

$P_{v}$ : vapor pressure $(\mathrm{Pa})$

$Q_{\text {in }}$ : flow rate at inducer path inlet $(\mathrm{m} / \mathrm{s})$

$Q_{\text {out }}$ : flow rate at inducer path outlet $(\mathrm{m} / \mathrm{s})$

$t:$ time (s)

$U_{t}:$ tip speed of inducer $(\mathrm{m} / \mathrm{s})$

$V c$ : cavity volume $\left(\mathrm{m}^{3}\right)$

$\delta$ : difference per time interval

$\triangle P f$ : pressure rise in front part by inducer head $(\mathrm{Pa})$

$\Delta P r$ : pressure rise in rear part by inducer head $(\mathrm{Pa})$

$\zeta$ : damping ratio

$\rho:$ density $\left(\mathrm{kg} / \mathrm{m}^{3}\right)$

$\sigma:$ cavitation number, $\sigma=2\left(P_{\text {in }}-P_{v}\right) /\left(\rho U_{t}^{2}\right)$

\section{SUBSCRIPTS}

0 : value obtained by approximate expression in Fig. 4

total : total value of whole inducer

\section{REFERENCES}

[1] K. Kamijo, T. Shimura and M. Watanabe, An Experimental Investigation of Cavitating Inducer Instability, ASME paper, 77-WA/FE-14, 1977.

[2] Y. Tsujimoto, K. Kamijo and Y. Yoshida, A Theoretical Analysis of Rotating Cavitation in Inducers, Trans. ASME, J. Fluids Eng., 115: 135-141, 1993.

[3] Y. Iga, M. Nohmi, A. Goto and T. Ikohagi, Numerical Analysis of Cavitation Instabilities Arising in the Three-Blade Cascade, Trans. ASME, J. Fluids Eng., 126: 419-429, 2004.

[4] C. E. Brennen and A. J. Acosta, The Dynamic Transfer Function for a Cavitating Inducer, Journal of Fluids Engineering, Vol. 98: 182-191, 1976.

[5] T. Shimura and K. Kamijo, A Study on Dynamic Characteristics of Liquid Oxygen Pumps for Rocket Engines (1st Report), National Aerospace Laboratory Technical Report, TR-725, 1982 (in Japanese). 
[6] S. Rubin, Prevention of Coupled Structure-Propulsion Instability (POGO), NASA SP-8055, 1970.

[7] T. Ujino, T. Shimura, Y. Kohsetsu and M. Niitsu, POGO Prevention of $\mathrm{H}-2$ Launch Vehicle, AIAA paper, AIAA-94-1624-CP: 2858-2867, 2009.

[8] T. Nakazawa, System Modeling \& Simulation, Journal of the Japan Society of Mechanical engineers, Vol. 113, No. 1104: 63, 2010 (in Japanese).

[9] T. Shimura, S. Kawasaki, M. Uchiumi, T. Kimura, M. Hayashi and J. Matsui, Stability of an Axial Thrust Self-Balancing System, ASME Journal of Fluids Engineering, Vol. 135, No. 1, 011105, 2013.

[10] M. Uchiumi, T. Horibe, T. Inoue, Y. Yoshida and K. Adachi, Excitation Force Modeling of Rotating Cavitation and Rotor Vibration Analysis of a Turbopump Rotor, 16th Cavitation Symposium, 2012 (in Japanese).

[11] M. Uchiumi, M. Shimagaki, S. Kawasaki, Y. Yoshida and K. Adachi, Integrated Design Method of a Rocket Engine Turbopump Sub-system for Suppressing Rotor Lateral Vibration, 28th International Congress of the Aeronautical Sciences (ICAS 2012), Paper No. ICAS 2012-4.3.4., 2012.

[12] T. Shimura, Geometry Effects in the Dynamic Response of Cavitating LE-7 Liquid Oxygen Pump, Journal of Propulsion and Power, Vol. 11, No. 2: 330-336, 1995.

[13] Y. Tsujimoto, Y. Yoshida, Y. Maekawa, S. Watanabe and T. Hashimoto, Observation of Oscillating Cavitation of an Inducer, ASME Journal of Fluids Engineering, Vol. 119: 775-781, 1997.

[14] B. Goirand, L. Collongeat, A. Dutertre and Ph. Morel, Vinci Fuel Turbopump Testing Activity Achievements, 4th International Conference on Launcher Technology "Space Launcher Liquid Propulsion", 2002. 